mentioned the need for full sterile precautions when inserting subclavian venous lines I hardly leave myself open to that particular criticism.

I maintain the virtue of using the narrowerspectrum antibiotic which is effective against the organism. As I mentioned in the article, the efficacy of the treatment is of course based on other things than the serum bactericidal level, but since adopting the practice of dropping the aminoglycoside in selected patients with sensitive viridans organisms I have had no case of failure to respond or recurrence which could be attributed to my practice of using penicillin alone. Gentamicin is quite a toxic drug particularly in the elderly and any opportunity to lose it in favour of a much more benign penicillin alone is good medical practice.

Celia OAkley

Royal Postgraduate Medical School Hammersmith Hospital London W12

\section{Falls and femoral fractures}

SIR,-Your leading article (19 August, p 522) deals with the immediate causes of falls leading to femoral fracture in elderly people -drop attacks, dizziness, etc. The only reference to conditions affecting fragility of bone is the suggestion that immobility of the housebound may accelerate the development of osteoporosis.

In a series of papers ${ }^{1-3}$ concerned with deaths from fractures and falls in the elderly in England and Wales, Scotland, and the USA I have shown a close relationship between mortality from falls and fractures of limbs. In the USA Iskrant ${ }^{4}$ concluded that deaths from falls appear to be positively associated with bone fragility. An analysis of annual mortality rates from falls showed notable changes in trends throughout this century, in both the UK and the USA. I suggested that factors influencing changes in mortality (characterised in the UK by a reduction in mortality in the decade of wartime rationing and austerity from 1941 to 1950 ) may have been improvements in general nutrition, particularly of growing young people, or in the vitamin $\mathrm{D}$ nutrition of elderly. Throughout the UK mortality of the elderly from falls is positively related to latitude and negatively related to average height. There is a similar relationship between urban and rural populations: elderly townspeople have a higher mortality from falls than people in the country.

Over the whole of this century annual variations in the mortality of old women from falls, in both the UK and USA, have been closely related to the much lower mortalities of old men $(r=0.90)$. The duplication of annual peaks and troughs in male and female mortalities suggests that some common and contemporary factors affected the mortality of each sex, even though the total experiences of mortality were substantially different. Examination of several other national statistics shows the same close relationship between male and female mortalities of the elderly from falls.

Deaths from falls of elderly American Negroes varied little from year to year. Their mortality was at a much lower level (between 15 and $50 \%$ ) than Caucasian mortality in the UK and America. This reflects the greater strength of the more robust bones of Africans and people of African descent.
It is not reasonable to suppose that these annual and class differences were due to a greater or less liability to falls. It is questionable whether the liability of the elderly to postural imbalance from the variety of causes outlined in your leading article would vary to correspond with the trends of mortality which I have described. It is even less likely that there have been corresponding changes in risks from slippery linoleum, loose carpets, and badly lit stairs. Some other external factor appears to have affected bone fragility in both men and women.

Hove, Sussex

T P EDDY

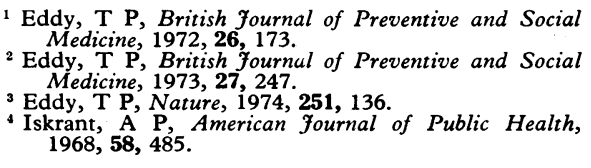

Asthma in children

SIR,-Your leading article (9 September, p 716) appears to excuse the underdiagnosis of asthma in early childhood. The reluctance to diagnose asthma in childhood is regrettable and harmful and can lead to confusion in the parents and under-investigation by the doctor. Parents welcome a definite diagnosis and thorough investigations to reveal precipitating factors. Most will despise platitudes and overtreatment with drugs.

The early identification of offending allergens is of prime importance and dictates the correct management based on their avoidance. For example, house dust avoidance measures, including enclosure of the mattress in a plastic cover, will eliminate nocturnal symptoms in over half the children with mitesensitive asthma and avoid the need for drug treatment.

We already know enough of the basic causes of childhood asthma to direct scarce resources to educational programmes and discerning tests of practical diagnostic value such as the detection of allergen-specific IgE in serum. The asthma label should no longer be feared but should herald the application of modern diagnostic knowledge and treatment, and every reassurance should be given to parents regarding the optimistic prognosis.

JAMES K SARSFIELD

Department of Paediatrics,

Harrogate General Hoste,

SIR,-The misjudgments of others are a happy hunting ground for specialists who wish to reinforce their prejudices with lurid anecdotes, and this practice is well illustrated in your leading article on asthma in children (9 September, p 716). Unfortunately the result is neither scientific nor educational and I became irritated by the generalisations. Surely medical audit is best conducted by those who have to face the problems and a leader on a subject as important as childhood asthma needs to be influenced by those caring for children in the community as well as expressing the views of respiratory physicians.

I was particularly interested in your vigorous promotion of a near-allergen-free environment by vigorous dusting and disposal of pets even in "the absence of any history and negative results of skin tests." It would be good to know how wide the net of obsessive attention to allergen hygiene should go-the child's bedroom, upstairs, the whole house, granny's house, friends and neighbours? If this is really necessary please let us have good evidence of its long-term efficacy in the general community of wheezy kids before we can take you too seriously.

Finally, neither Dr A N P Speight (29 July, p 331) nor you seem to be aware that the label "asthma" is not a necessary prerequisite to the use of bronchodilators and disodium cromoglycate in primary care. A large proportion of our work is done without hard diagnostic labels and evidence is accumulating to suggest that this is more desirable than to err in the direction of excessive labelling. Perhaps this difference of emphasis says something about the considerable differences which exist between the primary- and secondary-care doctor's experience of childhood bronchospasm and asthma. The tip of an iceberg reveals its presence but not the shape or environment of its body.

N C H StotT

Welsh National School of Medicine

General Practice Unit,
Cardiff

\section{Abuse of pentazocine}

SIR,-The short report by Drs A King and T A Betts (1 July, p 21) is not sufficiently clear on several important points. For example, what is meant by "increasing evidence"? In our experience there is no significant increase in the percentage of genuine pentazocine addicts. Apparently the authors mean the number of new notifications received over the years. An increase in the percentage would have to be proved using statistical methods.

The descriptions of withdrawal completely contradict international experience. The ease of pentazocine withdrawal is probably based on its position as an antagonist agonist, but strangely enough the authors have made no mention at all of this particular property of pentazocine, which constitutes a real innovation. I comment on withdrawal in more detail below.

In serious publications it has never been disputed that even pentazocine can cause dependence, but the dependence potential is generally indicated as being so low that subjection of the drug to narcotic controls does not appear justified. Experience from the USA shows that hard drugs are abused more frequently than pentazocine despite restrictions; therefore controls on pentazocine might serve simply to reduce the convenience of the drug but in no way to reduce the very low level of abuse. Moreover, one should not single out pentazocine in the case of a person who is dependent on many drugs. Logically several glues would then have to be subjected to controls; these glues are even more readily obtainable and have often enough been described as agents leading to later dependence.

The high proportion of medical personnel in the report (four out of six) suggests the possibility that drug substitution may be taking place in the majority of these cases, the medical personnel keeping for their own consumption the morphine derivative prescribed for the patients and giving pentazocine to the patients instead. Apparently, however, this possibility was not considered by the authors at all, yet the severe withdrawal symptoms observed strengthen our suspicion in this 